University of Nebraska - Lincoln

DigitalCommons@University of Nebraska - Lincoln

2009

\title{
Wolf Use of Summer Territory in Northeastern Minnesota
}

Dominic J. Demma

University of Minnesota, St. Paul

L. David Mech

USGS Northern Prairie Wildlife Research Center, david_mech@usgs.gov

Follow this and additional works at: https://digitalcommons.unl.edu/usgsnpwrc

Part of the Other International and Area Studies Commons

Demma, Dominic J. and Mech, L. David, "Wolf Use of Summer Territory in Northeastern Minnesota" (2009). USGS Northern Prairie Wildlife Research Center. 98.

https://digitalcommons.unl.edu/usgsnpwrc/98

This Article is brought to you for free and open access by the US Geological Survey at DigitalCommons@University of Nebraska - Lincoln. It has been accepted for inclusion in USGS Northern Prairie Wildlife Research Center by an authorized administrator of DigitalCommons@University of Nebraska - Lincoln. 


\title{
Wolf Use of Summer Territory in Northeastern Minnesota
}

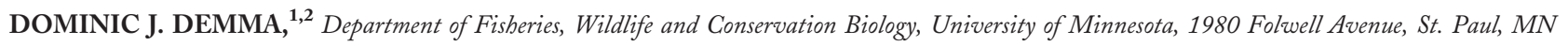 \\ 55108, USA \\ L. DAVID MECH, ${ }^{3}$ United States Geological Survey, Northern Prairie Wildlife Research Center, 8711 37th Street, SE, Jamestown, ND 58401-7317, \\ USA
}

\begin{abstract}
Movements of wolves (Canis lupus) during summer 2003 and 2004 in the Superior National Forest were based around homesites but included extensive use of territories. Away from homesites, wolves used different areas daily, exhibiting rotational use. Mean daily range overlap was $22 \%(\mathrm{SE}=0.02)$ and that of breeding wolves was significantly greater than for nonbreeders $(\bar{x}=25 \%$ and $16 \%$, respectively). Rotational use may improve hunting success. Managers seeking to remove entire packs must maintain control long enough to ensure that all pack members are targeted. (JOURNAL OF WILDLIFE MANAGEMENT 73(3):380-384; 2009)
\end{abstract}

DOI: $10.2193 / 2008-114$

KEY WORDS Canis lupus, homesites, Global Positioning System collars, movements, nomadism, radiotracking, rotational use, telemetry, wolves.

A distinctive characteristic of wolves (Canis lupus) is their capacity for travel. Few other mammals roam so widely on a daily basis (Mech 1970). Wolves' travel serves the 2 primary functions of obtaining food and maintaining their territory, and a wolf pack's annual cycle includes 2 seasonal movement phases: 1) homesite-based summer movements and 2) nomadic winter movements (Mech and Boitani 2003).

During summer, wolf movements generally center around the pack's current den or rendezvous site from which each adult radiates out to forage and then returns to bring food to the pups (Murie 1944; Mech et al. 1998, 1999; Jedrzejewski et al. 2001; Packard 2003). Breeding adults must forage and return to the den frequently to attend pups, which represent the pair's entire annual reproductive investment (Mech and Boitani 2003). Other pack members are tied to homesites as well, not only for care and feeding of pups (Packard 2003) but also to maintain social bonds to other pack members (Mech and Boitani 2003) and possibly to obtain food (Mech 1995).

During the day, den and rendezvous sites are likely to be attended by multiple adult pack members; however, breeding males frequent den areas less than breeding females, and den attendance of nonbreeding wolves is variable (Harrington and Mech 1982, Ballard et al. 1991). Although wolves may depart homesites together, they typically forage independently (Ballard et al. 1991, Mech et al. 1998, Demma et al. 2007) and return individually (Peterson 1977, Mech and Merrill 1998).

Most studies of summer wolf activity focused on a pack's use of den or rendezvous sites (Murie 1944, Harrington and Mech 1982, Mech 1988, Ballard et al. 1991). However, little is known about wolves' daily movements and spatial use of territories away from homesites. Mech et al. (1998, fig. 5.5) instrumented 2 wolves inhabiting caribou (Rangifer

${ }^{1}$ E-mail: dominic.demma@alaska.gov

2 Present address: Alaska Department of Fish and Game, 1800 Glenn Highway \#4, Palmer, AK 99645, USA

${ }^{3}$ Present address: The Raptor Center, 1920 Fitch Avenue, University of Minnesota, St. Paul, MN 55108, USA tarandus) calving grounds in Denali National Park, Alaska, USA, with Global Positioning System (GPS) radiocollars that collected hourly locations during a 2-week period. During and after the peak of calving, wolves fanned out from the den each day to areas used by calving caribou and returned using several different routes. Mech et al. (1998) concluded that the value of varying hunting routes might be to increase the chances of surprising more prey.

Jedrzejewski et al. (2001:1993) studied seasonal territory use by wolves in Poland using short-interval, ground-based radiotelemetry and found that, during spring-summer, wolves' movements were concentrated around homesites and that areas used on consecutive days overlapped "extensively." During autumn-winter, these wolves moved widely and used their territory in a rotational way, with a regular pattern of revisiting the same areas every 6 days on average. Jedrzejewski et al. (2001) concluded that rotational use is related to territory maintenance but may also help wolves to avoid prey behavioral depression. Charnov et al. (1976) termed behavioral depression of prey availability to describe a heightened awareness of prey in response to presence of predators, which is thought to lower hunting success of predators.

However, no one has examined summer spatial use of wolf pack territories elsewhere. Our objectives were to 1) examine daily movements of breeding and nonbreeding wolves and 2) assess for evidence of rotational use of wolf pack territories during summer.

\section{STUDY AREA}

We conducted our study in a $1,300-\mathrm{km}^{2}$ area in the central Superior National Forest $\left(48^{\circ} \mathrm{N}, 92^{\circ} \mathrm{W}\right.$; Fig. 1). Nelson and Mech (1981) provided a detailed description of the study area. Wolves occurred throughout the study area at densities of 30$36 / 1,000 \mathrm{~km}^{2}$ during the study (Mech 2009). White-tailed deer (Odocoileus virginianus) occurred at densities of 12-15/10 $\mathrm{km}^{2}$ (M. H. Dexter, Minnesota Department of Natural Resources, unpublished report) and constituted the major prey of wolves in the area (Frenzel 1974; Nelson and Mech 


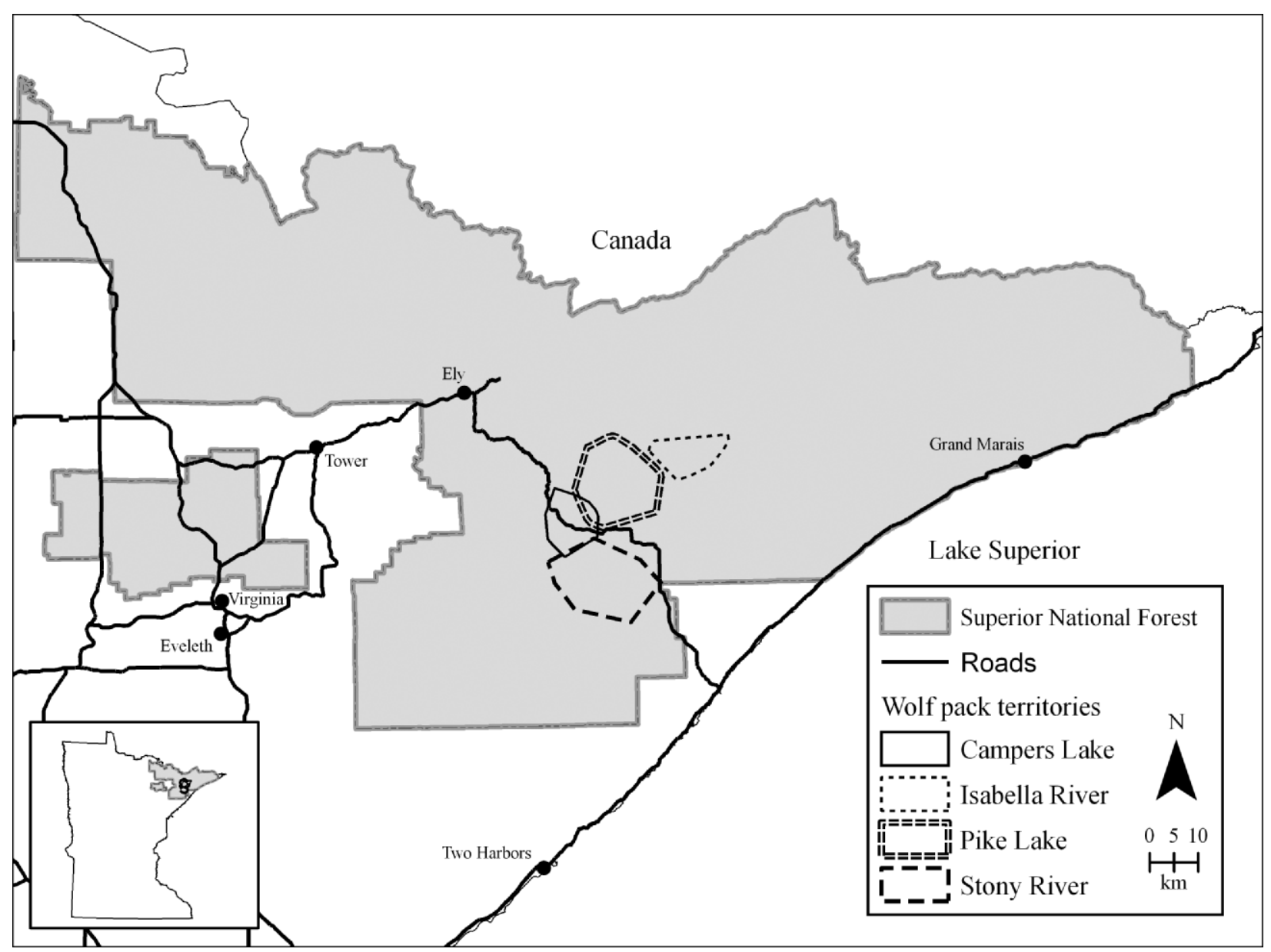

Figure 1. Summer territories of Global Positioning System-collared wolf packs studied during 2003-2004 in the Superior National Forest of northeastern Minnesota, USA.

1981, 1986), primarily fawns during summer (Van Ballenberghe et al. 1975, Nelson and Mech 1986, Kunkel and Mech 1994). Wolf packs inhabiting the area were the Campers Lake Pack, Isabella River Pack, Pike Lake Pack, and Stony River Pack.

\section{METHODS}

During May-July 2003-2004, we live-trapped, immobilized, and examined 8 wolves using standard techniques (Demma et al. 2007). We fitted wolves with store-on-board and remotedownloadable GPS radiocollars programmed to obtain locations at regular intervals (Advanced Telemetry Systems, Inc. [ATS], Isanti, MN; Televilt, Lindesberg, Sweden; and Vectronic Aerospace, Berlin, Germany): the 6 Televilt collars at 10-minute intervals and the single ATS and Vectronic collars at 15-minute intervals, 24 hours per day. We did not test whether location accuracy differed between collar types. We expected locations of all collars to be within $5 \mathrm{~m}$ and 30 $\mathrm{m}$ of the true location $50 \%$ and $95 \%$ of the time, respectively (Moen et al. 1997, Dussault et al. 2001). We deemed the expected location accuracy acceptable for determining daily ranges of wolves using our methods (see below).

To minimize any potential movement bias resulting from wolf capture and immobilization, we excluded GPS locations collected during the first 5 days postcapture. We also excluded from the spatial analyses a yearling female wolf (895) that dispersed from her natal territory 4 days into her study tenure. We plotted all GPS data in ArcMap and used Hawth's Analysis Tools (2007) to calculate daily ranges and movement characteristics.

We visually examined each wolfs GPS locations for dense clusters and considered clusters that wolves used recurrently as homesites (Mech et al. 1998, Jedrzejewski et al. 2001, Merrill and Mech 2003). We characterized homesite attendance for each wolf by determining which days they were present at homesites.

We determined daily ranges for each wolf by using the minimum convex polygon (MCP) method (Mohr 1947). We calculated MCPs for each 24-hour period (1200-1159 hr), using $100 \%$ of locations, and we considered these locations representative of minimum daily ranges of GPScollared wolves. We chose this common method because it was suitable for our objective of estimating the extent of daily home ranges without regard to density distribution of locations. Furthermore, the number of locations we used for determining daily ranges $(\bar{x}=63, \mathrm{SE}=1)$ and lack of large physiographic barriers to movements (i.e., no large voids) within wolf territories would minimize 2 of the main MCP biases (White and Garrott 1990).

We examined summer territory use by individual wolves. 
Table 1. Background data on Global Positioning System (GPS)-collared wolves instrumented for study during 2003-2004 in the Superior National Forest of northeastern Minnesota, USA. All wolf GPS collars were Televilt (Lindesberg, Sweden) with location attempt rate of one per 10 minutes except where otherwise noted.

\begin{tabular}{|c|c|c|c|c|c|c|c|c|}
\hline Wolf no. ${ }^{a}$ & Sex & $\begin{array}{c}\text { Age } \\
(\mathrm{yr})\end{array}$ & Pack $^{\text {b }}$ & GPS study period dates & $\begin{array}{l}\text { Study duration } \\
\text { (days) }\end{array}$ & $\begin{array}{l}\text { No. GPS } \\
\text { locations }\end{array}$ & $\begin{array}{c}\text { Mean location } \\
\text { interval (min) }\end{array}$ & $\begin{array}{l}\text { Location acquisition } \\
\text { success rate }(\%)\end{array}$ \\
\hline 883 & $\mathrm{~F}$ & 1 & PL & 3 to 5 Jun 2003 & 32 & 1,669 & 28 & 37 \\
\hline 889 & $\mathrm{M}$ & 1 & PL & Collar never recovered & & & & \\
\hline 893 & $\mathrm{~F}$ & 2 & $\mathrm{CL}$ & 11 Jun to $11 \mathrm{Jul} 2003$ & 30 & 2,126 & 20 & 50 \\
\hline 895 & $\mathrm{~F}$ & 1 & PL & 11 Jun to 3 Jul $2003^{c}$ & 23 & 1,009 & 29 & 30 \\
\hline 897 & $\mathrm{~F}$ & 2 & IR & 26 Jun to 9 Jul 2003 & 14 & 933 & 21 & 48 \\
\hline 901 & $\mathrm{M}$ & 2 & PL & 16 Jun to $17 \mathrm{Jul} 2003$ & 31 & 2,281 & 20 & 51 \\
\hline $881^{\mathrm{d}}$ & $\mathrm{M}$ & 8 & PL & 21 Jun to 7 Aug 2004 & 48 & 2,880 & 24 & 65 \\
\hline $899^{\mathrm{e}}$ & $\mathrm{F}$ & 2 & SR & 27 Jun to 3 Sep 2004 & 69 & 4,201 & 24 & 64 \\
\hline$i^{f}$ & & & & & 26 & 1603 & 24 & 43 \\
\hline $\mathrm{SD}^{\mathrm{f}}$ & & & & & 8 & 620 & & \\
\hline $\mathrm{SE}^{\mathrm{f}}$ & & & & & & & 2 & 4 \\
\hline
\end{tabular}

${ }^{a}$ Wolves 881,893 , and 899 were breeders; all others were nonbreeders.

${ }^{\mathrm{b}} \mathrm{CL}=$ Campers Lake; IR = Isabella River; PL = Pike Lake; SR = Stony River.

${ }^{c}$ Dispersed from natal territory after 16 Jun 2003.

d Advanced Telemetry Systems (Isanti, MN) collar with location attempt rate of one per $15 \mathrm{~min}$.

${ }^{\mathrm{e}}$ Vectronic (Vectronic Aerospace, Berlin, Germany) collar with location attempt rate of one per $15 \mathrm{~min}$.

${ }^{\mathrm{f}}$ Televilt collars with location attempt rate of one per $10 \mathrm{~min}$.

To assess for rotational use of territory we first calculated daily range overlaps of all consecutive 2-day intervals in each GPS-collared-wolfs study period. We then pooled the overlap data of all wolves to calculate a weighted mean of daily range overlap for all wolves, breeders and nonbreeders. We defined rotational use as the use of different territory areas daily and considered rotational use to be occurring if the mean daily range overlaps of wolves were $<50 \%$. We performed a 2 -sample $t$ test to test for differences in the mean daily range overlap between breeding and nonbreeding wolves.

To assess for regular pattern of use for individual wolves, we examined daily range overlap during all 10 -consecutiveday periods in each wolf data set. We determined daily range overlap between day 1 of the study period and each of 9 subsequent days (e.g., range overlap between days 1-2, days $1-3$, days $1-4$, and so on up to days $1-10$ ). Then, using day 2 as the initial day, we determined overlap between it and each of 9 subsequent days. We repeated this analysis by systematically treating all days in a data set as the initial day, then determining overlap between it and each of 9 subsequent days. Substantial increases in mean overlap of any day pairs relative to previous day pairs would be indicative of a regular pattern of re-use of territory areas during the period.

\section{RESULTS}

During 2 summers, we live-trapped 8 wolves from 4 wolf pack territories. During 2003, we captured and radiocollared 4 Pike Lake Pack members (2 M, 2 F) and one female each from the Campers Lake and Isabella River packs (Table 1). All wolves were 1-2 years old and showed no signs of breeding except for the 2-year-old female from the Campers Lake Pack that was lactating when captured. During 2004, we captured and instrumented 2 breeding wolves, an 8-yearold male from the Pike Lake Pack and a 2-year-old female from the Stony River Pack (Table 1).
We recovered 7 of 8 GPS collars. Mean GPS study period for Televilt collars was 26 days (range $=14-32$ days; $n=5$ ). The GPS study periods for the ATS and Vectronic collars were 48 days and 69 days, respectively (Table 1). Mean number of GPS locations for the Televilt collars was 1,603 (range $=933-2,281$ locations; $n=5$ ). The ATS and Vectronic GPS collars collected 2,880 locations and 4,201 locations, respectively. Mean location interval for the Televilt collars was 24 minutes ( $\mathrm{SE}=2, n=5)$, which was equivalent to that of both the ATS and Vectronic collars (Table 1). Location-acquisition success for the Televilt collars averaged $43 \%(\mathrm{SE}=4, n=5)$, and successes for the ATS and Vectronic collars were $65 \%$ and $64 \%$, respectively.

Global Positioning System-collared wolves used overall MCP areas of $100-396 \mathrm{~km}^{2}$ during their respective study periods. There was no relationship between study-period length and overall MCP size $\left(r^{2}=0.03, P=0.72\right)$. Location data sets of all GPS-collared wolves included 1-3 dense location clusters that were used recurrently, and we considered these to be homesites. Homesites made up $31 \%$ ( $\mathrm{SE}=5, n=6)$ of each wolf's GPS locations, on average. In cases where wolves had more than one homesite within their territory, they tended to use one homesite exclusively and then abandon it after moving to another. Breeding wolves $(2 \mathrm{~F}, 1 \mathrm{M})$ were present at homesites on $81-100 \%$ of days. Nonbreeders use of homesites was more varied. Wolf 897, a nonbreeding 2-year-old female, attended her pack's homesite on $79 \%$ of days. Two nonbreeding Pike Lake Pack members, wolf 883, a 1year-old female, and wolf 901, a 2-year-old male, were present at or near homesites on $34 \%$ and $58 \%$ of days, respectively.

Both breeding and nonbreeding wolves traveled extensively throughout their territories and tended to use different areas daily. Mean daily range overlap was $22 \%$ $(\mathrm{SE}=0.02, n=218)$ for all wolves. Average daily range overlap was greater $\left(t_{216}=-2.12, P=0.04\right)$ for breeders 
$(25 \%, \mathrm{SE}=0.03, n=143)$ than nonbreeders $(16 \%, \mathrm{SE}=$ $0.03, n=75)$.

There was no consistent pattern of re-use of specific territory areas by wolves during 10-consecutive-day periods. For each wolf, mean daily-range overlap declined between day-pairs 1-2 and 1-10, and although all wolves had daypairs where overlap increased relative to previous day-pairs, the increases were negligible $(\bar{x}=4.4 \%, \mathrm{SE}=1.4, n=18)$.

\section{DISCUSSION}

Spatial distribution of wolf movements was generally characterized by recurrent use of one homesite interspersed with travel bouts to other areas of wolves' territories. Our findings confirm those of numerous other studies (Murie 1944, Van Ballenberghe et al. 1975, Mech et al. 1998, Jedrzejewski et al. 2001, Merrill and Mech 2003) but provide considerably more detail. Use of homesites by wolves was variable. All 3 breeding wolves, and wolf 897, a 2-year-old nonbreeding female, showed extensive and regular use of homesites and were generally present daily. On most days, travels of all wolves present at homesites included using areas away from homesites. Homesite use by 2 nonbreeding members of the Pike Lake pack was less regular. Wolf 901, a 2-year-old nonbreeding male, used the homesite regularly, but his general pattern was to be present for periods of several consecutive days and then absent for similar periods. Wolf 883, a 1-year-old nonbreeding female, was present at the same homesite only 5 times for periods lasting 2 days each during the 32 days of her GPS study.

Regular use of homesites by our breeding females and variable use of these areas by our nonbreeding wolves is similar to that found in previous studies (Fritts and Mech 1981, Harrington and Mech 1982, Ballard et al. 1991). Van Ballenberghe et al. (1975) concluded that irregular homesite attendance was characteristic of breeding females but findings were based on only 1-2 location attempts per day so should be viewed cautiously. We found that although breeding females regularly traveled away from homesites, they were present at some time during almost every day.

Despite dens and rendezvous sites being the hub of their movements, the GPS-collared wolves regularly used different areas of their territory daily, which suggests that wolves use rotational use as a summer foraging strategy (Jedrzewski et al. 2001). During summer, vulnerable prey (primarily deer fawns and small prey) are available but they can be widely distributed, and wolves need to travel considerably within territories to forage (Demma et al. 2007). Mean daily-range overlap of breeders was greater than that of nonbreeders, likely a result of regular trips back and forth to homesites by breeders to care for and feed pups (Mech et al. 1999). Nonbreeding wolves are more variable in their presence at homesites; consequently, their movements tend to be more nomadic at times.

Although frequent use of homesites by breeders would require less extensive use of the territory on any given hunting foray, varying departure routes from the homesite would allow them to hunt previously unused areas. Because wolves apparently have a keen spatial map of their territory (Peters 1979), and varying their hunting routes to surprise prey could potentially improve their hunting success (Mech et al. 1998, Jedrzejewski et al. 2001), it seems likely that our wolves intentionally departed homesites to areas different from where they last returned, similar to what Mech et al. (1998) found. Varying of hunting routes by breeding wolves would also allow them to efficiently patrol and maintain their territory (Peters and Mech 1975, Jedrzejewski et al. 2001).

In our study area, 2 Pike Lake Pack members (883 and 901) had MCPs that overlapped $70 \%$ during the 19-day period when both were monitored; however, they were together for only $2 \%$ of locations (Demma et al. 2007). Although the wolves were infrequently located together and used distinct territory areas throughout the period, they were located in the same general area on 10 of 19 days, and both had locations at the same sites within 24 hours of each other on several occasions (Demma 2007), which suggests that although pack members rarely traveled together during summer, they still remained loosely associated at times away from homesites. Reasons for this are unclear, but one possible explanation is that they were visiting each other's kill remains (Demma 2007). How the distinct and variable nature of individual wolf pack members' movements during summer affects hunting success is unknown, but their irregular presence would likely help wolves maintain a level of surprise when hunting.

Whether wolves exhibit rotational use in areas where their primary ungulate prey are clumped during summer (e.g., elk or caribou) is unknown. Theoretically, wolves departing den areas to hunt should travel directly to areas of known high prey densities (e.g., calving grounds), but Mech et al. (1998) found that wolves hunting barren-ground caribou during and after the peak of calving fanned out from the den each day to areas used by calving caribou and returned using several different routes. Although these wolves typically hunted on the calving grounds, their variable daily routes are indicative of rotational use, at least while departing and returning to the den. Further research would help to characterize the extent of any rotational use of territories by wolves in these wolf-prey systems.

\section{Management Implications}

Wolves have now been delisted both in the Western Great Lakes Area, USA, and the northern Rocky Mountains, USA, and individual states are assuming management responsibilities such as controlling wolf depredations, which mostly take place in summer. Our study provides information about how individual wolves use pack territory and how each regulates its daily movements, which could help managers appropriately design their lethal and nonlethal control and management efforts. Thus we recommend that managers seeking to control or deter livestock depredations by entire packs during summer should maintain their efforts long enough to be certain they are affecting all pack members. 


\section{Acknowledgments}

This study was supported by the Biological Resources Discipline, United States Geological Survey, United States Department of Agriculture North Central Research Station, the $\mathrm{W} \& \mathrm{M}$ Foundation, the University of Minnesota, and V. Gates. We thank E. Can, J. Derbridge, B. Hanson, M. Harvey, M. Jager, S. Koehler, and M. Nelson for completing long hours of field work in often challenging conditions. Vectronic donated a collar for our testing.

\section{LITERATURE CITED}

Ballard, W. B., L. A. Ayres, C. L. Gardner, and J. W. Foster. 1991. Den site activity patterns of gray wolves, Canis lupus, in southcentral Alaska. Canadian Field-Naturalist 105:497-504.

Charnov, E. L., G. H. Orians, and K. Hyatt. 1976. Ecological implications of resource depression. American Naturalist 110:247-259.

Demma, D. J. 2007. Use of GPS telemetry to study wolf territory use and predation on deer fawns during summer in the Superior National Forest of northeastern Minnesota. Thesis, University of Minnesota, Saint Paul, USA.

Demma, D. J., S. M. Barber-Meyer, and L. D. Mech. 2007. Testing global positioning telemetry to study wolf predation on deer fawns. Journal of Wildlife Management 71:2767-2775.

Dussault, C., R. Courtois, J.-P. Ouellet, and J. Huot. 2001. Influence of satellite geometry and differential correction on GPS location accuracy. Wildlife Society Bulletin 29:171-179.

Frenzel, L. D. 1974. Occurrence of moose in food of wolves as revealed by scat analysis: a review of North American studies. Naturaliste Canadien 101:467-479

Fritts, S. H., and L. D. Mech. 1981. Dynamics, movements, and feeding ecology of a newly protected wolf population in northwestern Minnesota. Wildlife Monographs 80.

Harrington, F. H., and L. D. Mech. 1982. Patterns of homesite attendance in two Minnesota wolf packs. Pages 81-105 in F. H. Harrington and P. C. Paquet, editors. Wolves of the world: perspectives of behavior, ecology, and conservation. Noyes, Park Ridge, New Jersey, USA.

Hawth's Analysis Tools. 2007. SpatialEcology. Com home page. $<$ http:// www.spatialecology.com>. Accessed 31 Jan 2007.

Jedrzejewski, W., K. Schmidt, J. Theuerkauf, B. Jedrzejewski, and H. Okarma. 2001. Daily movements and territory use by radiocollared wolves (Canis lupus) in Bialowieza Primeval Forest in Poland. Canadian Journal of Zoology 79:1993-2004.

Kunkel, K. E., and L. D. Mech. 1994. Wolf and bear predation on whitetailed deer fawns in northeastern Minnesota. Canadian Journal of Zoology 72:1557-1565.

Mech, L. D. 1970. The wolf: the ecology and behavior of an endangered species. Natural History Press, Garden City, New York, USA.
Mech, L. D. 1988. The Arctic wolf: living with the pack. Voyageur Press, Stillwater, Minnesota, USA.

Mech, L. D. 1995. Summer movements and behavior of an arctic wolf, Canis lupus, pack without pups. Canadian Field Naturalist 109:473-475.

Mech, L. D. 2009. Long-term research on wolves in the Superior National Forest. In A. P. Wydeven, E. J. Heske, and T. R Van Deelen, editors. Recovery of gray wolves in the Great Lakes region of the United States: an endangered species success story. Springer, New York, New York, USA.

Mech, L. D., L. G. Adams, T. J. Meier, J. W. Burch, and B. W. Dale. 1998. The wolves of Denali. University of Minnesota Press, Minneapolis, USA.

Mech, L. D., and L. Boitani. 2003. Wolf social ecology. Pages 1-34 in L. D. Mech and L. Boitani, editors. Wolves: behavior, ecology, and conservation. University of Chicago Press, Chicago, Illinois, USA.

Mech, L. D., and S. B. Merrill. 1998. Daily departure and return patterns of wolves, Canis lupus, from a den at $80^{\circ}$ latitude. Canadian FieldNaturalist 112:515-517.

Mech, L. D., P. Wolfe, and J. M. Packard. 1999. Regurgitative food transfer among wild wolves. Canadian Journal of Zoology 77:1192-1195.

Merrill, S. B., and L. D. Mech. 2003. The usefulness of GPS telemetry to study wolf circadian and social behavior. Wildlife Society Bulletin 31: 947-960.

Moen, R., J. Pastor, and Y. Cohen. 1997. Accuracy of GPS telemetry collar locations with differential correction. Journal of Wildlife Management 61:530-539.

Mohr, C. O. 1947. Table of equivalent populations of North American small mammals. American Midland Naturalist 37:223-249.

Murie, A. 1944. The wolves of Mount McKinley. U.S. National Park Service Fauna Series 5. U.S. Government Printing Office, Washington, D.C., USA.

Nelson, M. E., and L. D. Mech. 1981. Deer social organization and wolf predation in northeastern Minnesota. Wildlife Monographs 77.

Nelson, M. E., and L. D. Mech. 1986. Mortality of white-tailed deer in northeastern Minnesota. Journal of Wildlife Management 50:691-698.

Packard, J. M. 2003. Wolf behavior: reproductive, social, intelligent. Pages 35-65 in L. D. Mech and L. Boitani, editors. Wolves: behavior, ecology, and conservation. University of Chicago Press, Chicago, Illinois, USA.

Peters, R. P. 1979. Mental maps in wolf territory. Pages 119-152 in E. Klinghammer, editor. The behavior and ecology of wolves. Garland STPM, New York, New York, USA.

Peters, R. P., and L. D. Mech. 1975. Scent-marking in wolves: a field study. American Scientist 63:628-637.

Peterson, R. O. 1977. Wolf ecology and prey relationships on Isle Royale. U.S. National Park Service Scientific Monograph Series 11, Washington, D.C., USA.

Van Ballenberghe, V., A. W. Erickson, and B. Byman. 1975. Ecology of the timber wolf in northeastern Minnesota. Wildlife Monographs 43.

White, G. C., and R. A. Garrott. 1990. Analysis of wildlife radio-tracking data. Academic Press, San Diego, California, USA.

Associate Editor: Conner. 